\title{
Pilte Setomaalt
}

Teekäija märkmed. 19.-23.august 1996

\section{$\underline{\text { Mari-Ann Remmel }}$}

Üleeile siis tulime Setomaalt, piiri tagant. (Peab vist ikka otsast alustama, mitte tagasitulekust). Kõrvus heliseb veel vokaalharmoonia, pehme, vuliseva ja naksuva seto keele kõla, mida kirjakeelde kuidagi ümber panna ei saa. Kirjakeel tundub kohe kange ja lame, ei leia nagu õiget tooni, kuidas Setomaast kirjutada.

Päevad olid soojad ja südamlikud nagu sulavõi, öised kirbud pipraks sekka. Samas see kurbus ja mahajäetus nagu soolvesi kõige viljakandva üle. Päälevalguv "vindläse vaim".

Andsime ja saime. Võib-olla oleks pidanud rohkem andma, olema ise vahetum, kannatlikum. Aga mis teha, kui veri ja temperament teine.

Üldisemat veel - kui oled naine, siis pane Setomaale minnes seelik või kleit selga ja rätik pähe (või varuks) - tunned end kõige paremini. Nokkmüts, mille palava päikese varjuks kaasa võtsin, mõjus väga tobedalt. Nagu juudi suvitaja, tõepoolest!

Ja pimedal augustiööl võõras lakas aset sättides on hea, kui oled varustatud taskulambiga. Meie polnud.

\section{Esimene päev}

Petseri buss väljub Tartust kell 9 , kollane "Ikarus". Räpinas ronime välja, ostame pudeli siidrit (viimane ost eesti raha eest) ja sööme murul lesides võileibu Näpi vorstiga. On mõnus ja unine olemine.

Koidulas on ülesõidu remont, kuid buss lastakse siiski läbi. Eesti passikontroll toimub ühes putkas, vene poolel seevastu on pompöössed valged ehitised, läikivad marmorpõrandad. Täidame tollideklaratsiooni, vene keeles.

Petseris on kohe kerjus bussi vastas, norib raha. Me ei anna, ta on väga jota välimusega. Õieti on kogu linnal üsna samalaadne väljanägemine - rääbakil, tolmune... kurvavõitu kuidagi. Asume otsima panka ja muid asutusi, mille kohta Ergol on juhtnöörid. Mina ei tea midagi, vahin niisama ringi. Kott on kole raske ja ilm hirmus palav.

Rahavahetusega on jama. Üks shaakalinäoga tüüp püüab meile mingit tehingut kaela määrida. Vahepeal külastame miilitsaid, kes täna enam jutule ei võta. Lõpuks saame raha vahetada - kumbki 200 krooni.

Bussijaamas käime peldikus. See polegi kõige hirmsam. 
Irboska-Pihkva bussiga sõidame Ozera-Utja peatusse. see on umbes kolmas või neljas peatus Petserist. Pilet maksab 2300 rubla. Buss on täis, istmekatted võidunud, õhus hõljub imal okse või kalaraipe hais. Uhh, palav kleepumine!

Kobime maha ja ongi järv, sügaval all oru põhjas. Ilus. Venelased ujuvad ja kilkavad. Otsime õiget teeotsa. Kitsuke rada läheb läbi heina järve äärt pidi. Kõrgete ohakate kohal lendlevad valged seemnetutid, tükkides silma ja igale poole. Kohati meenutab vaatepilt lumesadu. Samas on väga palav. Ergo võtab jalad paljaks ja vahetab pikad püksid lühikeste vastu.

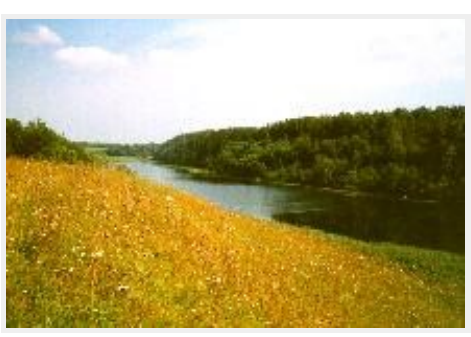

Enne Unkavitsa küla korjavad kaks naist oruveerel mingeid taimi, korvid või kotid seljas ja rätid peas. Rühime neist mööda. Nad on liiga kaugel, et juttu teha.

Küla vahele jõudes ajab Ergo uuesti sündsamad säärekatted jalga. Vaevalt sellega valmis saanud, märkame lähenemas üht tädi, kes lükkab enda ees ratastatud 40-liitrist veeämbrit. (Sääraseid veevedamise riistu oli näha Petseris ja mujalgi). Küsime, ega ta juhuslikult Savi Veera pole. On küll. - A kost ti tiiät? - Aga eks Heiki juhatas meid siia, sinu juurde. - Ah tuи must habõnik? Ja provva oll' ka üteh? Ma jo eemält kai, ôt keäq nuиq "tarto kottega" tulõvaq! (s.t raamikatega).

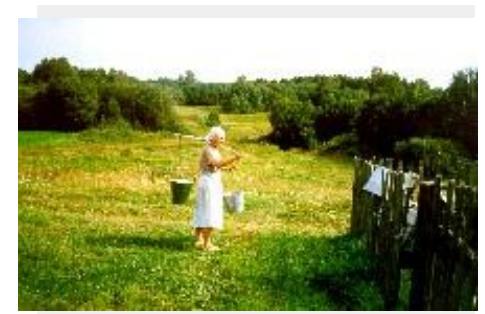

Väega illos tädi. Täitsa päris, kavalad silmad. Juhatab meid tsässona juurde, ise läheb kaevule, mis asub pisut eemal. Oma kaev on tal sisse sadanud, joogivett peab kaugelt vedama. Tsässon on põõsaste taga peidus. Seinad on lagunenud, aga katus korralik. Tabalukk on ees ja pühane ukse kohal, rist katuseviilu küljes. Lävepakuks lai kivi.Tillukesest aknast sisse piiludes paistab kivirist, kusagilt põllult sinna toodud. Pühaseid ei ole. Nähtu mõjub siiski. Oleme kohale jõudnud.

Pildistamiseks sobivat nurka otsides mõtlen: huvitav, kas Heikil ja Ulrikel, kelle jälgi mööda me ju esialgu käime, on täpselt samasugused pildid võetud? Või näevad inimesed samu asju siiski liiga erinevalt... Kostab kabjaplaginat ja vankrikolinat. Lähenebki hobune, vankril istub vanamees. Pildistan. Ergo arvab, et vast läksid ka kaevule. Veera läheb veekäruga enne koju kui meie tsässona vahtimisega valmis saame. Ta ei taha, et teda pildistatakse - ehkki ta just nõnda, nagu ta on, ongi kõige kenam. Valge õhuke rätt, hele sitsiseelik ja pluus, põll. Jalas tennised. Väikeste kavalate silmade ümber on palju naerukurde, kongus tugeva nina all välgatavad üksikud metallhambad.

Veera majapidamine on juba ära müüdud "pihkvalisile", ise ajab Eestisse elamatuleku asju (nagu paljud teisedki setud). Asjaajamine on väga vaevaline, sest vene keelt ei osata.

Istume õuel pingi peal ja tunnistame tillukesi hooneid. Siinmail on kõik ehitised hulga väiksemad kui Eestis. Elamine on lihtsam - ma ei tea, kas viletsam on õige sõna, võib-olla kasinam, vähenõudlikum. On pikk kõrvalhoone, kuur heinte jaoks ja kaks sauna - üks vana, teine uus. Mõlema uksel on mitu söega tehtud risti. Nähtavad ristid on ka heinasaral ning maja sisemisel uksel, mis viib eluruumidesse.

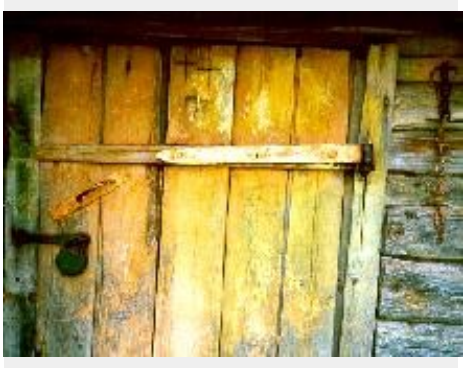


Heiki ja Ulrike (rõõmsa näoga ja eestläseq!) on siin hääd vastuvõttu leidnud ja nii ka meie. Veera kutsub külalised tarre, räägib (ei, kõnõlõ õks!) oma elust ja lehmast, kelle nimi on Kirsi ja kes talle otsekui perekonna eest on. Tõsi küll, paar koeranässigi kuulub siia perre. Üks neist pidavat vist küll "vindläne" olema, venelase koer. Haugub meie peale hoolimata sellest, et me eestlased oleme. Või just sellepärast? (Imelik, et ka koerad on Setomaal väikesed. Ei näinud me ühtegi suuremat "murdjat", kui üks suvitajaile kuuluv hurt Vilo külas välja arvata).

Tare nurgas tillukese laua ääres külma piima rüübata ja võileiba süüa on tõesti õnnis tunne. Ruum on soe - igas mõttes - ja saialõhna täis. Veera on küpsetanud võrratu, kollase ja vetruva krõbeda koorikuga saia. "Süügeq, süügeq!", sunnib ta nüüd meid ja seda me teeme. Toome ka oma toiduvarusid lauale. Pisut häbelikult küsib Veera, kas ta võib ühe tomati võtta. Ja uudistab meie siidripudelit. Ulatan talle maitsta seda "limonaadi", mille ta väga hääks hindab. On kuidagi piinlik -et, näe, mis meil kõik on. Mul on kahju, et ei oska Veerale tema emakeeles seletada, et seda, mida tema meile pakub, ei saa osta ühestki poest. Isegi Eesti Vabariigis mitte.

Muidugi jääme Veera poole öömajale. Aga enne käime ümbrust uurimas. Ilma suurte kottideta seekord. Astume Pööni ja Kol'o pole. Võtame kaasa vaid ujumisriided ja muu tehnika. Maa on tühi. Üks must hobune on tee äärde köide pandud. Pööni küla majad on väga vaiksed, inimesi ei paista. Ergo juhib mu tähelepanu mädanenud kartulitele, millega on auklikku külavaheteed tasandatud. Lagunenud talli juures teeme väikese peatuse, et ihulikke pakitsusi leevendada. Järve ei paista kusagilt. Astume edasi, üks auto sõidab meist mööda. Eesti numbriga. Kol'o külas näeme ühel õuel inimesi, nii noori kui vanu. Küsime, kuidas järve äärde saab. Meile antakse saatjaks kaks asjalikku poissi, nii mõneteistkümneaastased. On siin vanavanemate juures, muidu elavad Võrus. Küsin ühe käest, miks ta vanaemal jalad kinni seotud olid. (Ümber pahkluude olid valge marlisidemega mähitud mingid taimed). Saan vastuseks, et vanaemal on sammaspool ja et takjalehed pidavat aitama. Poisid juhatavad meid üle heinamaa orupervele, kust laskub kitsas rada võsa vahele. Peagi läheb võsa üle kõrgeks kuusemetsaks, mis palavuse eest mõnusat varju pakub. Metsaalust katab pehme ja soe, päikeselaike täis tipitud samblavaip, otsekui kutsudes pikali viskama. Millegipärast me seda ei tee. Vaatan läbi objektiivi, et metsa ilu pildile ei mahu. Siiski vajutan päästikule. Aparaadi automaatvälk rikub loomuliku rohelise hämaruse.

Kuuskede varjust välja jõudes näeme järve, või õigemini kuuleme algul. Kostab valju vene muusikat, supluspaigas peesitab trobikond suvitajaid. Järve kaldal asub Kuutsina küla. Vahetame roostes raudpaadi varjus riided ja oma väärtasju teatud ebalusega rõivaste alla jättes sammume mööda kõrkjaalleed heledasse savisogasesse vette. Vaatamata läbipaistmatusele tundub vesi võrdlemisi puhas ja parasjagu soe. Oleme tänulikud Heikile, kes meile nõnda kuurortlikud jahimaad jättis. Enesetunne muutub hulga värskemaks.

Tuldud teed me enam tagasi ei lähe, võtame jalge alla tolmuse raja, mis viib üles küla juurde. Tõesti, see oleks väga kaunis paik, kui kõrget kallast ei risustaks roostetavad kolakad, mille algset otstarvet ei oskagi ära arvata. Teeme juttu kahe tüdrukuga, kes siin suvitavad. Üks on Petserist, teine Tallinnast. Küsime teed Unkavitsa külla. tüdrukud räägivad eesti keelt, ehkki jutukam seletaja on vist rohkem venelane. Käsib meil minna õkva ja siis vasakule ja siis paremale jne. Teine tüdruk (kui kuuleb, kes me sellised oleme) arvab, et meil peaks kindlasti auto olema. Või vähemalt jalgratas. Kuuleme, et selles külas setosid õieti pole. Tülitame ka üht vanapaari, kes panevad parajasti mingit ehitist palkidest kokku. Sedapuhku on vaja vene keelt. 
Metsateel küll autoga midagi teha ei oleks. Orus voolab puhas ojakene. Möödume vesiveski varemeist ja turnime ojakividel. Teiselpool oja kasvab tohutu jäme vana paju. Nopin mõne metsvaarika. Ergo leiab kaks kõrvuti veskikivi, ühe august kasvab välja karusmarjapõõsas. Ronin kivi otsa ja pildistan. Varsti jõuame taas metsa. Siingi on kuused, aga samblateki asemel vohab metsa all vaarikaräga ja lehtpuuvõsa. Oja jookseb meist paremal, kohati on vulin kuulda. Tee peal on palju konni. Tuleb ka purre, käsipuuga ja puha. Olemegi Ungavitsa mail. Küla lähedal kasvab mahlakas ristik, "nii et söö või ise" - ütleb Ergo. On's tal kõht tühi? See mure saab varsti murtud.

Läheneme Veera majale teisest küljest. Kurepesa juba paistab. Ronime läbi ohakate ja satumegi Veera heinamaale. Kirsi juurde. Koer hakkab haukuma. Samal õhtul olen kirja pannud järgmised read:

Õhtu. Natuke juba hämar. Sirtsud siristavad. Kõht on täis ja väga rambe olemine pärast päevast matka. Ega me muud ei olegi suurt teinud, kui matkanud ja söönud. Pääsukesed vidistavad ja peni haugatab vahel. Ergo ka kirjutab, kui lesime siin Savi Veera hainu pääl, kus on kaks ööd veetnud ka Heiki ja Ulrike. Tädi võttis asemetegemist väga südamega, käskis Ergot värsked heinad ilusti laiali laotada ja ise peal "trullida", nagu oli seda teinud ka Heiki. Noh, et mees tegi aset ja "provva" (s.t Ulrike) vaatas päält.

Veera tuli just lehmale heinu niitmast. "A kule, ti võtat lindi pääle, võipolla tulõ vana aig viil tagasi..." - astub Veera meie juurde päris tõsise näoga. Nõjatub piidale ja räägib usust, jumalaarmust.

"Vinne rahvast om ôks rohkõmb mi kerikoh kah, taah Petserih, maastera poolõ minnäq. Paasapäävast katõ nädäli peräst om maar'apäiv. Võeh, om rahvakeist! Papp', ku ta laul', sis kyik kumahti! Kyik pilises, preestriq!"

On nii pime juba, et Veera nägu ei paistagi, ainult jutt, nii "illos" jutt, et minusugune on võimetu seda üles kirjutama.Kuidagimoodi püüan seda teha.

"Tat'o-tädi tulõo" - hüüatab Veera. Naaber - Õuna Tat'o, üle 80-aastane armas pisike tädikene on meid, tartlasi, vaatama tulnud. (Koer on tal samasugune kui ta ise, väike valge tuustik, väga sõbralik). Tat'o on ka muidu Veera pool sage külaline. "Ma mõtlõ, õt tulõ viil määne vana aig tagasi", ütleb Veera nüüd ka Tat'ole. Et kui me võtame kõik vanad jutud ja kombed lindi pääle, et siis tulebki ehk vana aeg tagasi. Ei saa aru, kas ta mõtleb seda tõsiselt. Tundub küll.

Veera räägib oma elust: "Ma olõ'i hüvvä ello nännüq, kõgõ olõ tõmmanu tüüd. Rikkilõ tõmsi." Vihjetest saame aru, et Veera on elus nii mõndagi läbi elanud. Tugevat mõju on avaldanud sündmus, mille tagajärjel tal nüüd pruun rist rinna pääl olevat. Pikne löönud linakakmisõ aig.

Seisame tükk aega pimeduses sara ees ja jutt jookseb nobedasti. Enne aeti meid kui väsinuid magama. Viimaks kolime öötaeva alt tuppa, Veera on särtsu täis ja tahab meile kangesti viina pakkuda. Kahetseb kibedasti, et ei julgenud seda Heiki ja Ulrike juuresolekul teha, arvates, et "säändseq isikuq", nad vast viina ei joogi! (Ju siis meie tundusime prostoimad). Veera teab: kui oled väga väsinud, siis on hea natukene viina võtta. See aitab. Veendume peagi, et jutt on õige. Väsimus hajub ja põhjamaine veri sulab. Tare on rõõmu täis. Ergo tegutseb minidiskiga ja tädid ei 
lase ennast sellest suurt segada. Hoian ühe käega pitsi ja teisega mikrofoni. Ergo peab kallama, sest tema on poiss. Viin teeb naised ülemeelikuks ja jutukaks. Õhatakse liikva järele. Aga "sis olt uumera, ku liikvat ja viina segämini juvvaq". Arutame ka rahaasju ja hindu. Tuleb välja, et sõit Tartost Petserihe mass puultõist putõlt viina. Veera lõõbib, et kui ta Eestisse on kolinud, siis hakkab ta tihti Setomaal külas käima (üldiselt kurdavad kõik, et sõitmine on kalliduse tõttu võimatu). "Ma naka käuma! Ma võta viisa! Raha jal saa. Raha nagu seeneq kasuse."

Rahaga seoses tuleb juttu Veera isast, kes olnud surres 52-aastane, ning patriarhaalsest majandamisest. "Isäl om üts rahakott. A ku mitu rahakotti om majah, sis tulõ nälg! Peremiis juht'!"

Venelaste kohta öeldakse, et "mil olliq umma vindlasõq". Praegusi venelasi, kes ida poolt tulevad, kardetakse nagu vargaid. Neid ei või usaldada. Küsime, kuidas Veera venelastega suhelda saab, kui ta keelt ei oska.- " Noh, ma ütle, ôt mine võta säält vedroo ja vadaa ja vadaa daljookaja..." Küll nad aru saavad! Ega setodki kõik ühtemoodi ei räägi. Veera ja Tat'o naeravad Saatserinna rahvast, kes sõnu pikaks venitavat: "Mi kõnõlõ: tulliq ja lätsiq, a n'ooq ütleseq: tullivaq ja lätsivaq.".

Kõneldakse ka vanadest aegadest. "Vanaaega peedi pulmõ - puudalitsõq pudõliq tuudi, pirruq palliq." - "Vesi ja tuli piät olõma!" (ilma nendeta ei saa). - "Siih koeti kangid. Õga talo kudi. Õgah taloh koeti." - (Vanadest laste mänguasjadest:) - "Sis muud olõ-s latsil ku vana luits ja pulgakõnõ". Kuuleme, et "vana Eesti aigu oll' ka vargid. Varastedi põllõq iist (põll oli peenikesest villast, helmeid ja pitsi täis), lõigadi paalaq takast ja varastedi ärq."

Kui soojast tarest väljume, on sügav öö, tähed siravad taevas. Ergo küsib midagi tähtkujude kohta meelde jääb vaid, et siingi on Sõel, seto keeli Sõgõl. "Määnegi zirk" huikab üha, nii üdini kaeblikult. Igatahes ei ole ta kakk, sest siis oleks asi hull. Veera ütleb: "Kakk, ku majah laul ja ikk, sis kaos är' kotuski!" Ning teab kohe ühe näiteloo pajatada. Ei taha õueski jutt lõppeda. Räägime nimedest, minu nimi jääb neile hästi meelde, pidi vana seto nimi olema. Kui ütlen, et mul koguni kaks nime on, lausub Veera: "Võeh, sa olt sis väega rikas inemine!" Eks ole Ergolgi kaks nime, aga see ükski ei mahu hästi seto maailmapilti. Tõeliselt rikka inimese enesetundega vajume oma pehmele asemele.Mähime ukse seestpoolt traadiga kinni. Ei ole mingit hirmu, ukse peal on söega tehtud ristid ja "poisi hais majah". Hommikupoole hakkab seina taga kikas kirema, muidu on uni hää. Veera antud rätt hoiab pea soojas ja kaitseb kõrvu putukate eest. Mind ei söögi ükski kirp. Ergot aga küll. Ta nimelt harutas oma magamiskoti lahti, mida mina targu ei teinud.

\section{Teine päev.}

Hommikul on Veeral pää veidi haige.Sellest hoolimata on ta varakult jalul, toimetab Kirsiga. Tore on läbi une kuulata, kui asjalikult ja samas südamlikult ta oma "lehmäkesega" kõneleb. Eestimaal pole ma säärast suhtlemist kuulma juhtunud.

Tat'o on ammu läinud, kui me ükskord üles saame. Oleme otsustanud tagasi Petseri minna, ikka sellesama va miilitsa pärast, mis ainult kella üheni lahti on. Veera keedab meile mannaputru. Eeskojas on tal gaasipliit, mis suvel toidutegemist hõlbustab. Pliidi kõrval seisab suur potitäis punaseid pohlamarju - keegi on talle toonud. Mõtlen, keda ta mulle meenutab oma käbeda ja tarmuka olemisega. Võrdlusena kerkib lapsepõlvest esile Kunksmoori kuju. 
Peale gaasipliidi on Veeral teisigi kodumasinaid: nurgas külmkapp (seal hoiab ta piima) ja ahju kõrval samovar. Soemüüril sibavad väikesed prussakad. Veera kurdab, et talle linnaskäimine ei istu - pää hakkavat bensiinivingust valutama. (Ometi oli Petseris mu meelest äärmiselt vähe masinaid liikvel, võrreldes praegusaja Eesti linnadega. Tema õnn, et ta tipptunni ajal Tallinnasse pole sattunud. Veera kuulub veel vanasõnade ja hobuste aega, mis siin Setomaa pärakülades inimesipidi hingitseb.). Sõnad on kõik teistmoodi (tõistmuudu): sõir, võid, kopakõnõ, küdsätämä, tsuklõma jne... Ennist oli juttu, kas me tsukõlda mõistame (ujuda, noh!). Tema vajuvat põhja õkva nagu kirves.

Veera tuleb meid saatma, et näidata kätte teeotsa Podlesje bussipeatusesse. (Oleme lubanud talle tuua leiva ja pudeli viina.) Teel avaneb järgmine vaatepilt: paks venelanna on jalgrattalt maha tulnud ja katkub tammepuud. Tamm on suur, oksad kõrgel, eit ei ulata hästi. Nii kui meid näeb, karjub Ergot appi. Veera seletab mulle, et tammeviht peab saunas kaua vastu. Venelane on hirmus, tuleb peale nagu tank. Ta nimi on Inna. Tünderjas tagumik dressipükstes, higine (ilm on jälle kuum) poisipea ja prillid. Suitsetab ja paljastab üha hambaid - lõputuks naeratuseks. Hakkab meilt kohe küllakutset välja pressima. Rahast ei näi ta puudust tundvat. Ta on üks neist, kes siia külla on endale "suvila" ostnud. Kutsub Ergot endaga kaasa, et näidata, kus ta maja on. Vahepeal saan Veeralt kuulda, et Inna üks suur elueit on.

Jätame Veera teeotsale, meie rada viib mäenõlvakust alla. Korraga kuulen teda hüüdmas: "Mari!" Keerame ringi. Väike sale tädi seisab eredas päikesevalguses keset kõrbevaid põlde. - "Tuuge mullõ puul killo vorsti ka!" Mitte seda pekitükkidega ainult... Ta hääl kaob sinise põuase taeva alla. (Sääl juba keegi ei lindista....või just sääl.... imelikud mõtted tükivad pähe. aga olukord on nii iseäralik mu jaoks. Pärast aastast kodusistumist.)

Bussipeatusesse tuleb pisike räpane kõõrdsilmne tüdruk. Tunnistab meid süüdimatul pilgul. Küsin, mis ta nimi on. "Katja". Kui vana ? Laps tõstab neli sõrme. Pidasin teda umbes poole nooremaks. "Gde võ zivjoote?" - See on ainuke küsimus, millega ta meie poole pöördub. Buss ka ei tule ega tule ja ükski auto peale ei võta. Teen pilti Katjast ja ühest teisest tüdrukust, kes näeb välja nagu printsess tuhkatriinu kõrval. Lõpuks saabub buss.

Petseris on käik number üks miilitsasse. Tublid vene tädid istuvad laudade taga, tükk kolm. Kõik võtab kõvasti aega. Akna tagant kostab kanade kaagutamist. Helesinine interjöör ja arvelauad, ei ühtki arvutit ega ekraani, üksnes kartoteegid, sulepead, liimipotid kontoriliimiga, ka lillepotid - elusate lilledega kusjuures. Pärast kurnavat asjaajamist puhkame pangas jalgu ja siis kloostrisse.

Pärast jääb aega üle ja me üritame päevikut pidada. Kirjutan üles värskeid muljeid:

"Petseris, jälle! Palav, täiesti palav, pilvitu leitsak. Istume bussijaamas. See on kärbseid täis. Petseril on täiesti nõukogulik ilme. Peldik on suletud. Eile istus seal valves üks tädi, kes luges piiblit. Ergo vestles äsja ühe onuga, kes osutus eestlaseks (mitte setoks) ja üpris seniilseks. Läks vaatama, kus voorimees on. Aga mis põhiline - käisime kloostris, katakombides, kaua-kaua, küünlad käes. Mustades riietes ümarik tädi rääkis kummalisel uinutaval toonil - see polnudki nagu tavaline vene 
keel, ma ei saanud peaaegu midagi aru. Muutusin üha uimasemaks. Pimedad käigud otsatu hulga haudadega. Mul oli peas Veera kõige ilusam punane rätik, kuldniitidega. Ka bussis nähtud jaapanlased(?) olid kloostrisse jõudnud, ehkki neil olid jalas lühikesed püksid. (Kloostris antakse laenuks seelikuid, rätte ja salle.) See tüdruk, kelle kohta Ergo üleval ütles, et "ma olen vist imelik, aga sellised tüdrukud mulle meeldivad", oli ka all. Väikest kasvu, ilmetus jakis ja rätt lõua alla sõlme seotud. Hoidis väga omaette, seinte ligi, silitades käega hauaplaate. Ühe juures põlvitas ja palvetas peaaegu pisarsilmi.

Klooster on nagu rahusaar. Võtsime pühast kaevust vett oma tühja siidripudelisse. Üks vigane poiss koos paari vanema naisega oli ka kaevul. Temagi käis koobastes ja suudles käikude lõpus paiknevaid pühapilte. Kloostri sissekäigu juures olid kerjused valvel, andsime neile natuke paberrublasid. Nende nägudest võis näha, et Jumala nimel rahaküsimine joomatõve puhul igati tulus tegevus

on.

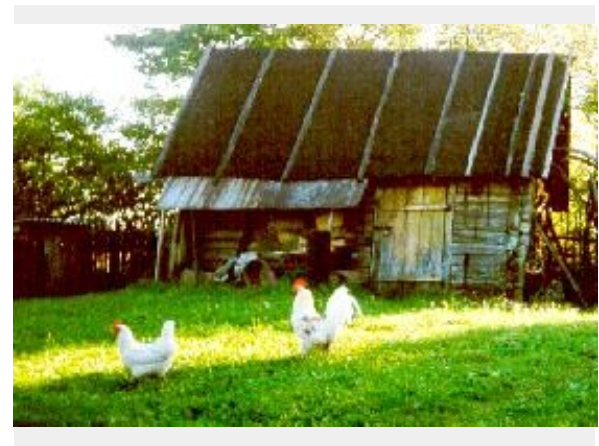

Õhtu. Istun Veera "suvilakese" trepil ja vaatan, et vana "sann" on nii ilus oma ukseristidega. Õhtune päike heidab õuemurule säravrohelise vöödi. Mõtlen, et peaks pildistama ja teengi seda - siis kui ka kukekene ja Veera ainus kanakene kaadrisse astuvad. Teen plõksu ja samas kahetsen - sekundi murdosa võrra hiljem on kukk jõudnud päikesevalgusse, mis paneb ta sabasuled eredalt särama. See sära minu pildile ei jäänud.

Maja uksel on taba ees, Veera on läinud vee järele. Ergo läks talle vastu ja appi. Nii vaikne on siin ja mahajäetuse tunne. Tühjad söötis väljad, sekka ka mõned põllud, kus viljakoristus pooleli. Elumärke on vähe. Oleme ise ka nii uimased ja väsinud sest palavusest ja võibolla ka natuke eileõhtusest viinavõtmisest. Saime ju magama alles kella kahe ajal. Tädid - Veera ja Tat'o - tahtsid kangesti pudeliga juttu puhuda. Olin just enne Ergole maininud, et küll on hea, et siin napsi ei pakuta.

Näe, Veera tuli! Hõikab mulle tervituseks: "Tere Mari, vana kere! Jumal tänätu, tütär karatu !" Lõpp mu päevikupidamisel."

Vaja on pildistada Veerat ja Kirsit, see on Veera soov. Ta läheb tuppa ja ilmub sealt välja uue "imidzhga" - rohelises krimpleenkleidis ja punamummulises rätikus. Arvab, et tumedam riie paistab pildi peal ilusam. Pildistamine, see on ju pidulik ja erakordne sündmus. Vähemalt siin, Setomaal. Punakaspruun lehm harmoneerub õhtuvalguses Veera tavatu kostüümiga päris hästi ja ma teen mitu plõksu. Need on viimased värvipildid.

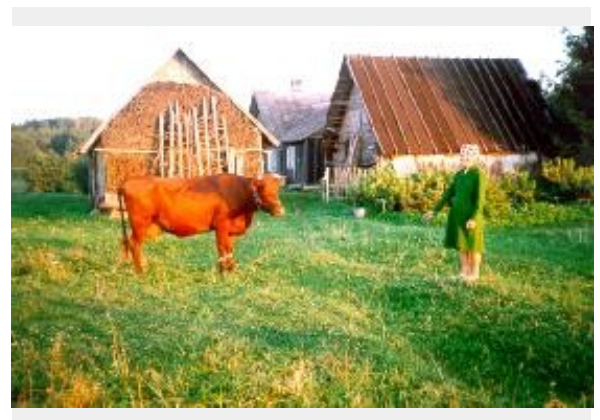

Tööd tahavad ka tegemist. Peenrad tarvis kasta, Kirsile rohtu niita. Pakume abi, mis tänuga vastu võetakse. Märkan majaseinal kaelkooku rippumas. "Kannipuu", ütleb Veera. Võtame selle ojale kaasa, tahan proovida, kuidas on sellega vett tassida. Veera arvab küll, et see käib mul üle jõu, aga mul on meeles pilt, kuidas ta eelmisel õhtul kergel sammul orgu siirdus, tühjad veepanged nagu mängeldes üle õla visatud kannipuu küljes tantsimas. 
Täis pangedega ei ole asi aga kaugeltki lihtne. Tasakaalu hoidmine näib lausa võimatu, nõuab ilmselt aastatepikkust harjutamist. Veera võtab riistapuu oma hooleks ja rühib ainult veidi kiiremini hingates mäest üles. Seda teed tuleb käia mitu korda, sest muld on väga kuiv. Maa lausa tolmab. Taimed, mida me kastame, on tegelikult venelaste omad. Veera arvustab viisi, kuidas peenrad on tehtud, kuid vett veab ikka. Sellise põuaga iga päev.

Ergo mõistab ka vikatiga ümber käia. Niitma läheme naabermaja lähedusse, sääl elavad venelased, kes oma eluaseme ümbrusele üldse rõhku ei pane. Majast pole aru saada, kas seal ülepea kedagi elab. Veera seob Ergo niidetud rohuhunniku kablaga kinni - nöörist jääb vaata et puudugi - ning üritab seda õlale visata. Ergo jõuab tast ette ja säärane lasu oleks ka tädi jaoks liig. Veera ohkab: oleks iga päev noor mees abiks!

Tahaksin väga Veerat joonistada, aga oleme kõik väga väsinud. Pealegi on vaja veel pohlad keeta. Veera vist häbeneb ka natuke oma väljanägemist, joonistamine on tema jaoks ilmselt veel tavatum ja seega hirmsam kui pildistamine. Siiski on ta veidike meelitatud ka ja lausub mulle tunnustavalt: "Ah sa olt sis joonistaja. Sul om sis hää nutt' otsah!". See on kompliment mittemillegi eest. Veera pilk on väsimusest hall. Vana sauna tagant tõuseb terav noorkuu .

Viinavõtmisest keeldume otsustavalt, eelistades und. See tuleb kohe. Seon ööseks jälle rätiku pähe. Rahulik öö.

\section{Kolmas päev}

Hakkame suhteliselt varakult astuma, et pääseda kuumusest. Rohi on veel märg, jalad lirtsuvad. Kott kah kuidagi kergem. Veera kuju kaob ohakate taha, tema mannapudru aga püsib veel mõnda aega kõhus. Hea hommik.

Miks ma ei pildistanud Veerat, kui ta uduses hommikuvalguses õues nõusid pesi! See oleks olnud kõige ilusam foto. Alati on parimad, õigeimad pildid need, mis tegemata jäävad. Hetki ei saa püüda. See on nagu pimesikumäng. Või umbes sama tunne kui unes, kus kunagi ei lähe makk käima ega funktsioneeri fotokas just siis, kui kõige rohkem vaja oleks. (Huvitav, kas see on tüüpiline folkloristi unenägu?) Esimene mustvalge pilt sai hoopis Veera majast, alt oru poolt vaadatuna. Veera veel küsis, et kas ikka tema kadajad ka peale jäid. Jäid küll. Üks kõrge, teine kogemata maha niidetud ladvaga. Kodu juures on kõik tähtis.

Kuutsinas ütleb unest üles raputet tüdruk (seesama lahke, Petserist!), et siin setusid ei ole ja tema sõbranna vanaisa elab "vot seal kaugel, läbi metsa jne....". All järve ääres ei paista hingelistki. Ei lähe ka meie ranna rahu rikkuma. Edasi minnes jõuame männimetsa - see meenutab Elvat - ja alles siin põikame alla vee juurde. Metsa all vedeleb konservikarpe ja muud prahti. On lõkkeasemeid ja telkimisjälgi. Paadisillake on pehkinud, vesi madal, tume ja mudane, ei meelita sugugi.

Järgmises külas üritame teed küsida. Lõpuks see ka õnnestub. Maja, mille sihikule võtame, on üleni piiratud võrkaiaga. Hõikame üle aia. Naine hüüab tuppa: "Kol'ka, idii sjudaa, naada pa estonski gavaritj!" Tuleb välja laadna olekuga mees, käterätt õlal. Lahke sõbralik kohalik venelane, kes 
talvitub Tallinnas. Jeesti keel vabalt suus. Ergo küsib, kus on Jugo küla. Mees pole kuulnudki. Silkab abivalmilt naabri poole. Tagasi tulles teatab: "Aa, Uussova Garaa!" See on Jugo küla venekeelne nimi.

Kol'ka seletusi järgides astume varsti Luha Vaska õuele. Vaska on möödunud aastal surnud . "Liiga palju töötas," on venelase arvamine. Kombaini ta surigi. "Vot tema oleks teile palju rjaakinud!". Kui vana see Luha Vaska siis oli? - " Noh, nii umbes 65-aastane. Olga, tema naine elab seal."

Oodatud 60-aastase naise asemel seisab maja ees kepile toetudes küll pealtnäha veidi vanem tädi. "Perenaist ei ole kodus, läks vallamajja," - ütleb ta. Seletame, kes me oleme ja mida soovime. Vanainimene on kuidagi ehmunud või väsinud või.... Kuuleme, et ta on 93-aastane (!) ja silmad peast ära nutnud. "Poiga ei olõq!" Oleme leina majas. Meie ees on Luha Vaska ema. - "Hää poig oll', armastas Jumalat." Memm pühib silmi. Ta on tõesti väga vana ja väga kõhn, päris kokku kuivanud. Aga meeled on selged ja mälu ka. Kurdab, et ei jõua enam midagi teha, aga minia, hää inemine, annab süüa ja hoolitseb ta eest. Ei jõua rääkidagi enam õieti.

Lisaks poja kaotusele on isegi nii vanal inimesel piiri asi südamel. - "Meil om vilets elo väega! Lasta-i latsi kodo tüühü appi. Piät massma!"

Hoolimata väsimusest kutsub Luha Mari meid kirsipuu varju istuma ning soostub meiega juttu ajama. Algne kohkunud olek hajub, kuid näha on ,et ta tõesti ei jaksa . Aga see, mis ta räägib, on väga arhailine seto pärimus - just usu ja valguse poole päält. Vanahalvast ja puugist ei taha ta kõnelda, ta nagu polegi lasknud endasse neid tumedaid asju. Olen rabatud - rääkides legendi Saalesja kiriku kohta, võrdleb meid inglitega, kes "samasuguste teekäijatena" maa peale tulid. Rändajad - nagu meiegi. ja teekäijale antakse süüa - see on "pühälik". Siin ongi siis vastus küsimusele, miks peab külalist kostitama.

Perenaine Olga tuleb rattaga koju. Ta on lesk, kannab musta rätikut. Väga-väga heade silmadega naine. Ta kutsub meid kohe tuppa ja katab laua. Tõstab taldrikutäied kapsasuppi, lõikab leiba ja oma saunas suitsetatud pekki. Külma piima ja võid võtame kõrvale.

Maja on ruumikas, uuemat moodi. Vaska ehitatud. (Siingi tegi sõda kõik maatasa). Köögikapi kohal on pühapilt, mitte nurgas, vaid lihtsalt seinal, ilma rätita.

Vanaema on puhkama läinud, perenaine istub meie juures köögis ja räägib. Ta ei saa kuidagi üle oma leinast, jutt käibki peamiselt surmast (ended, unenäod). Küsin seto rõivaste kohta. Et kas nüüd ka nendes maetakse. Olga vastab, et kuidas keegi tahab. Et nad on väga "rassõq, nuuq seto rõivaq". Olga enda ema maeti tavalise kleidiga, ei tahtnud nii raskeid surirõivaid.

Olga on väga siiras ja sümpaatne naine, ehkki mitte enam nii vanaaegne. Siiski tuleb tal üks oma vanaema muinasjutt meelde - lugu haavapuu tekkimisest. Kuidas verised lained randa uhtusid.... Haab on lesenaise puu. Olgal lähevad jälle silmad märjaks. Õnneks töötab nüüd ka minu diktofon, sest Ergo pani sellele patareid sisse. Minu akud millegipärast ei funktsioneerinud ja seetõttu ei jäänud Vaska ema jutust mitte midagi lindile. 
Kui oleme söönud, tõuseb vanaema ka jalule. Söandame paluda tal veelkord samu asju kõnelda, et neid minidiskile võtta. Maria on nõus ja me salvestame palju püha juttu: Jeesusest ja ühe poolega kalast, kolme käega Maarjast, Saalesja Troitsa kirikust, viimsestpäevast. Jugo küla kalme kohta räägib ta: Kalmõ kuusõq ommaq. Sääl ei künnetä. Neid ei tohi kiäki puttu.

Memm saadab meid Jumala õnnistusega teele ja ütleb: " Elo om nigu unõnägo maa pääl. Piät hää olõma kõigilõ..." ja et "keegi teine ei kõnele teile siin Jumalast nõnda kui mina.." Ja tal on õigus. Teist niisugust inimest me ei kohta.

Lõpetuseks teeme pilti. Maria säeb end ilusti istuma ja ütleb: hää käsi peab peal olema. Puusärgis ka.

On lõunase lüpsi aeg. Olga on musta leinaräti asemel pähe pannud tumepruuni.Pildistan tedagi kaevu ääres koos lehma ja lastelastega, kes üldist kurba meeleolu on leevendama tulnud. "Lapsed on mu rõõm ja rikkus," ütleb Olga. Tal on neli last, vast meieealised umbkaudu, kõik Eestis ja tublid inimesed. Noorim tütar pidavat ka kirikus käima, oli läinud Tartus luterlikku leeri. Ema ei pannud seda sugugi pahaks, et ta vene kiriku asemel luterliku valis.

Lahkume Troitsa küla ainsate setode juurest järve suunas. Alla orgu avaneb ilus vaade - keskel tee, kahelpool järved. Troitsa järves pidi olema vesi ujumiseks liiga külm, allikaid täis.Ega me üritagi. Teiselpool järve paistab juba Jugo küla e. Uussova Garaa. Külad on siin nii ligistikku, et ei jäägi aega hinge tõmmata - kui seda just ise ei võta. Päike kõrvetab. Keerame vasakule, kus mitu majapidamist ridastikku. Üks neist olevat miilitsa suvila, (noh miilitsatel suured palgad...). Valime korraliku kollase maja, mille juures kasvab ilus üksik mänd. Kuuri otsasein on üleni täis laotud värskeltlõhutud puid. Siis näeme ka inimesi. Oru pervel kase all istub pisut isevärki seltskond palgivirna otsas. Kaks naist, vanem ja noorem, ning üks patsidega plika. Ei puudu ka meeshing meile juhatatud Hõbõsaar Ivvan (63- aastane), kel naine "ullimajah". Ergo teeb mehega juttu, naised põrnitsevad meid altkulmu. Oleme häirinud nende mõnusat viinaviskamist naabrimehe seltsis.. Jutt venib pikale ja viinapudel, mis meie saabudes varjule pandi, tõuseb taas eide suule. Et me aga ikka ära ei märka minna, teeb õrnem sugu ise minekut. Eesti-setukeelne vestlus ei köida neid põrmugi, ju nad siis "vindläseq "on. Ivvan ei tee nende minekut märkamagi. Tuleb meile teed juhatama, arvates nagu ikka, et tema midagi erilist ei tea. Kõne voolab kui vallapääsnud vesi, sisaldades igasugu vanaaolisi asju. Jah, nii keel kui meel on tal väga setoliku olemisega. Väga kõhn on ta, nagu kuivanud kohe, aga samas sitke. Peas on tal vanaaegne päevinäinud nokkmüts, selline nurkadega, nagu mu vanaisal noorpõlve piltide peal. Mütsinokk varjab kissis silmi, millest vist üks koguni pime on. Vähemalt avanematu. Mees on nagu pisut närviline,vehib kätega ega suuda oma juttu katkestada. Keel tundub väga arhailine - väljendid, kõla, kõik. Ta on nagu sild uue ja vana aja vahel. Püüab omal moel mõtestada vana seto pärimust, mille keskel ta ise on üles kasvanud. Meie õnneks mitte haritud inimese kombel. Näiteks arutleb ta omal moel, miks küll lapsi vanasti nõnda "peteti" ja "meelitati". Et see hakkab ju väga närvi pääle lapsele. Ise nagu hästi ei usu neid olendeid, aga päris ilma nendeta ka läbi ei saa. On suur unenägude nägija. Mõtlen, et tavaliselt räägivad seda tüüpi asju vist naised. Aga Ivvanil on tütar surma saanud autoõnnetuses. Tsigand (mustlane) näed ennustas, et ei ole õnnelik sõit.

Võtan seljakoti maha, Ergo teeb varsti sedasama. On tõesti väga kuum ja mees kõneleb, kõneleb, kõneleb... Vahel panen diktofoni kinni ka. Mees räägib orjaajast (!), vanadest kalmetest, sõdadest et siit on mitu sõda samu jälgi pidi läbi käinud. Ja hunte olnud vanasti palju. Üks õpetaja jätnud 
lapse peale tunde. Hilja koju minnes söönud aga hundid lapse ära. Lapse isa vihastanud õpetaja peale nõnda, et lasknud ta püssiga maha. Vot sääne lugu Setomaalt. (Lindi peale see vist ei saanud.)

Ei tea kui kaua seal teeotsal seisame, üle tunni kindlasti. Tähelepanu hajub päikeselõõsas ja hoolimata tundest, et millegi /kellegi tõelisega parajasti silmitsi seisad, jätame järsult hüvasti.

Ergo arvab, et päike on ta ära pistnud. Ei ole ka kuhugi varju minna. Suure maantee ääres on üks suur kuusk ja pisut võsa kivisel maalapil. Kuidagi ei tõmba see koht. Pärast selgub, et see on rootsi sõja kalme. Lähedal on talu, teeäärsele postkastile on kirjutatud Fedorov.

Taamal paistavad Keera küla katused. Liiga ruttu olemegi küla vahel. Peab jälle suhtlema. Vasakut kätt on kollastest päevakübaratest ja peenardest ümbritsetud palkmaja. Kusagil aias vilksatab matsakas dressipükstes naisterahvas, kes oma pääd on ehtinud punase siidrätiga nõnda, nagu seda vaid venelased oskavad. Tegemist on Keera Kull'o miniaga. Kull'o ise istub seina ääres varjus, näost kahvatu ja pigmendilaiguline. Süda on haige, meiega juttu ajada ei taha. Me pole ka just parimas vormis. Näib, et selles majas on võim venelaste käes. Üks jõngerman uudistab meid ukse vahelt. "Vinne latsõ", ütleb Kull'o. Astume edesi.

Kalda Veera õuel on üks noorem mees - poeg, kes meile sugugi oma ema näidata ei taha. Silmitseb nii poolkavalalt ja annab meie küsimustele ühesõnalisi vastuseid. Hiljem kuuleme, et ta ongi üks "petjä poiss". Kes teab. Kui ei, siis ei. Nüüd oleme küll väsinud. Otsustame, et Luikperede poole ei lähe, kuna seal vigaline lats pidi olema ning seetõttu meid tarre nagunii ei lasta. Nende maja on ka väga räsitud moega. Aknad õieti ei paistagi kõrgete sirelipõõsaste tagant ja katus - see küll vihma ei pea. Kõrvalhooned kah laiali vajumas. Õuelt vaatab meid suur tume hobune.

Vajume pisut eemal põõsaste alla maha. Tee ligi küll, aga liiklus on siin nii väike, õieti peaaegu olematu. Sööme Veera saia, joome vett ja logeleme. Ergo jõuab isegi und näha. Arutleme, et ei tea, miks see Keera küla nii ebasõbralik on meie vastu. Põõsastestki tuleb paha haisu.Tasapisi vajub päev madalamale ja jõud hakkab taastuma. Kobistame taas teele. Teekäijad me ju oleme. Siin, selles ruumis.

Õdak. Siinsamas ja eikuskil. Piiri taga. Mitmeski mõttes. Aga kui taas hüppan sinna kinnipüüdmatusse olnusse, siis näen karja sitaseid lambaid pagemas üle tolmuse tee, vibalik naine madjakaga kannul. Kohe-kohe on sumisev õhtu, rammestus jalgades ja peas, jälgime toimuvat nagu filmi, vanu kroonikakaadreid - ning meile sajab kaela venekeelne rämedalt süüdistav sõnavaling. Justnagu peidaksid meie kotid kõikvõimalikku varastatud kraami. Sinise jakiga punasekirjus kleidis naine on määratlematu eaga, vist noor. Näol nautlevate eluviiside kustumatu pitser. Sõnakuulmatud lambad on, nagu näha, kaua pügamata, paksu kasuka küljes tolknevad sõnnikukärakad, mis jooksu taktis üksteise vastu puutudes tasakesi klõbisevad. "Kuhu need lambad peavad minema?" hõikab Ergo vastuseks sõimule. Tal on sisemine tundmus, et naine mitte venelane ei ole. Vaikus. - "Oi Issand jumal, te olete eestläseq!" Oi kui häbi tal on, et ta on meid sõimanud. Nüüd on ta see-eest lahkus ise. Eestlaste maine on siin kõrge. Seevastu venelased tulevat ja varastavat päise päeva ajal puud-põõsad tühjaks ja kiskuvat juurikad põllult üles. Kui me oleks venelased olnud, oleks ta meile mööda sääri andnud nii et... 
Seletame, kes me oleme ja mida siin teeme. Naine on väga jutukas. Kuna oleme teel meile veel tundmatu Kalamees Veera poole, ühtib me teekond uue tuttavaga, kes peab minema oma lehma juurde. (Lehma nimi on Laidi). Ronime läbi ojaaseme, mis on tõesti purukuiv.(Kuivuse üle kurdetakse pea igas peres, mõnedel pole kaevuski õieti vett).

Paistabki üks ümarik tädi oma pruuniksvärvitud maja ees. Juhatused klapivad - ta ei kuule peaaegu üldse. Läheb tuppa kuuldeaparaadi järele. Sellest pole palju abi. Lambaajaja tuleb meile järele, võtab endale vahendajarolli. Istume maja äärde pingile, sätime juttu ajama, aga peagi selgub, et see on tulutu ettevõtmine. Veera on juba noorena olnud halva kuulmisega ja seetõttu pole tal sellistele küsimustele nagu "Kas oled kuulnud, et...," midagi vastata. Kui selgub, et kuuldeaparaadi patarei on tühjavõitu, võtab Ergo kui tõeline ingel kotist uue patarei ja vahetab vana välja. Tädi nägu särab õnnest: "Oi, kui hästi ma nüüd kuulen!" Ta jääb siiski kohmetuks ja sõnakehvaks. Seevastu noor naine, kes meie vastas kükitab (pisut siivutult, taban ma end mõtlemas) ja suitsu pahvib (seda tänu Ergo tikkudele. Mida me küll Ergota peale hakkaksime!), - tema pulbitseb rääkidatahtmisest, kiites ka oma ema jutuandi.

Ja nii tulebki meil ikkagi Luikperede juurde minna, sest nõnda on määratud.

Hakatuseks tuleb tavaliselt juttu igasugu kotustest . Nüüd on kõne all Jugo kalme, mida meie teejuht soome(!) sõja aegseks peab, soome või rootsi või... mis vahet seal ikka on! Tunnen sees iseäralikku jõnksatust - midagi paljutõotavat on avanemas. Siin vist ei ole karta hariduse hukutavat mõju rahvapärimusele. On ju tõesti häid külgi ka igal halval asjal...

Kõnevool on suunatud rohkem Ergole, mina jälgin, jälgin... Huvitav tüüp omamoodi. Ei saa ma lahti harjumusest silmitseda iga inimest kui võimalikku modelli, salvestada pilguga ta näojooni ja ilmeid. Ühe näos domineerivad silmad, teisel nina... Tol naisel aga oli huvitav... ei leiagi õiget sõna... kas hambumus või koon või... Selles oli midagi metsikut, metsloomalikku, nagu kogu ta olekus. Pisut sassis juuksed... jah, temas valitses mingi segadus, mis kuidagi ei haakunud ta lahke käitumisega, mis kummatigi mõjus loomuomasena. Oli see tingitud üksnes sellest, et ta "nakas juuma ja poistega kamandama", nagu hiljem küla pealt kuulda oli tema elukäigust? Kummaline siiruviiruline segu heast ja kurjast.

Naine räägib palju elust-olust külas, kirub venelasi ja kiidab eestlasi. Vabandab, et lambad on niitmata - emal on jalg haige, ei saa midagi teha ja isa tervis ka vilets. Ise olevat ta kõigest paar nädalat kodus olnud. Õuel näeme ka üht 15-aastast poissi. Tema küll vigane ei paista, pigem heasüdamlik ja lapselik. Suu on ema moodi. Meid juhatatakse traditsiooniliselt maja seina äärde pingile, kõrgete sirelite varju. Naine tõttab ema kutsuma. On jõudnud talle juba seletada, mis meid huvitab. Oleme ka nagu pisut tuttavad - meie ees on vana Luha Mari tütar Olga, kadunud Vaska õde. Paks ja haige jalaga, oli ema ta kohta öelnud. Väimeestki kohtasime juba Troitsa külas.

Jällegi üks vastanditest koosnev abielupaar. Mees on näost hall ja haige, hingab korinal (sureb hilissügisel). Vaevalt paar lauset kuuleme temalt. Ta teeb tööd ja vaikib. Olgal aga jutt "juusk". Lindistamisega jäädakse ruttu nõusse ja nii istubki Ergo minidiskiga tädi kõrvale. Tütar kükitab trepil, läites järjekordse sigareti. Minul on diktofon kogu aeg peos. 
Olga määratleb end inimeseks, kel on huvi ja kes on kõike tähele pannud. Arvab, et kõik inimesed ei ole sellised. Oma ema kohta ütleb ta ka, et too on teistsugune, rohkem vagameelne. Kes teab, kust Olgale säärane loomus antud. Isast? Oleme Ergoga mõlemad üsna pahviks löödud, jõuame vaevalt noogutada ja sekka mõned küsimused poetada - sedavõrd vägev on pärimusetulv, mis siin laokil tare ja põõsaste vahelises poolhämaruses valla pääseb. Vaatame nagu nõiutult tee poole, mida mööda alles hiljaaegu tulnud hallides rõivastes puuk või tont-teab-kes. Tütar lisab trepilt sama värvikaid seiku. Palun tal lähemale istuda, ise võtan tabureti ja satun - plaksti - Olgaga silmsidemesse. Tal on sinised silmad, peab end nõrga verega inimeseks. Sellest hoolimata volksatab ta aegajalt vaadata nõnda et.... ta nagu teaks ise väga hästi, milline mõju neil juttudel on. Voh!

Siin tunneme, et vanahalvad, puugid ja essütajad, rääkimata nõidadest ja sobijatest - et kogu see seltskond on veel täies elujõus ja tegutseb - isegi päise päeva ajal. Tütar ütleb: ema, sa oled ju alati öelnud, et keskpäeval ei tohi metsa minna. Ja ükskord.... ja nõnda edesi.

Imelik, väga imelik maja. Natuke hirmutav. Ergo terane kõrv tabab toast lapse nuttu. Ja tuppa meid tõepoolest ei kutsuta. Sellest hoolimata püüab noor naine igati heastada oma hiljutist käitumist. Pakub öömajagi - heinte pääle muidugi. Võtame endale mõtlemisaega. Jätame kompsud sinnasamasse põõsaste alla ja jalutame Jugo poole tagasi, et rootsi kalmet lähemalt uurida. Õhtul on hea kõndida, ilm laseb hingata. Madal päike paistab läbi põllult tõusva tolmupilve, nii et kiirtejoad on selgesti näha. Traktor veel nii hilja põllul! Kalme asetseb kündmata saarena põlluservas. Kalmekuuskedest, mida keegi puutuda ei tohi, on ainult üks järel. Maa on täis ebaühtlase suurusega kive. Kas siingi on olnud kunagi kivirist? Midagi erilist silma ei hakka. Teeme paar pilti. Kohti on mõnikord raskem pildistada kui inimesi. Eriti kui nad varjavad oma nägu.

Oleme sõja jälgedel (mõtlen Hõbõsaare Ivvani lausutule). Kuigi - kes teab, kui vana see kalme tegelikult

on.

Tagasi pöördudes oleme öömaja-asja otsustanud. Ergol on küll mõningaid kahtlusi, aga kuhu sa vastu ööd ikka minema hakkad.

Vaatame üle ka kohaliku Liinamäe, mis asub otse Keera küla taga (Sandra suunas) lagedal väljal, sovhoosi maal. Hein on tegemata, ohakad üle pea. Noorperenaise sabas kahlame läbi torkiva rohu. Teeme siis ka kättpidi tutvust oma teejuhiga - tema nimi on Malle (Multsar), aastakaid 38.

Mäge ei ole. vaid mõned pliidihunnikud, millest maaparanduski pole jagu saanud... "Kiviq ommaq pliidiga koetuq," ütles Olga. Eesti keeles ütleks paekiviklibu. Kivikuhilad on kolmes kohas. Umbes jalgpalliväljaku suurune ala, arvab Ergo. Taamal, metsa veeres on Sandra küla, mida enam pole. Suured puud näitavad talukohti. Malle jutustab, et ühe talu vanaperemees uputatud kaevu. Ei mäleta, mis asjaoludel. Veel jutustab ta paar pikantset lugu eesti naisest, kes setole mehele läks. Põhiliselt räägib ta Ergoga, mina sörgin fotokaga sabas ja koos nad ka pildi peale jäävad kesk Liinamäge. Malle, märgates, et pildistan, astub päris Ergo ligi - et las siis vaatavad, et ta ühe "seto mutiga" koos on. See intiimne hetk jääb minu poolt kahjuks jäädvustamata, kuid Malle rõõmuks teesklen nupulevajutamist.

Plaanime veel ujuma minna. Järve vesi on külm, ujumas käiakse lüüsis - paisjärvekeses, mis on tekitatud järviühendavale ojale. Janek, Malle poeg, käsutatakse meile teed näitama. Mallel endal on 
toimetamist, lubab veel "kardohkit" keeta. Janek meiega ei suhtle, hoiab mitu meetrit ettepoole ja läheb kohe tagasi, kui on oma ülesande täitnud. Lüüs ei ole kalmest kaugel, paremat kätt teekaldast alla, oru põhja. Vesi on peegelsile ja puhas, puud pakuvad varju. Oleme ainsad suplejad. Romantiline koht. Ergo tuleb veest, tilkuv ja karvane nagu vetevaim. Mul võtab enda märjakskastmine rohkem aega. Õhk on juba jahedavõitu. (---)

Malle lüpsab parajasti lehmi, kui me tagasi jõuame. See toimub õues. Pole tal pinki ega midagi, lihtsalt kükitab hooletult nisasid sikutades lehma all ja samal ajal vestleb meiega. Ei ole tal nüüdki rätti peas. Teine, musta värvi lehm on rahutum kui punane Laidi ning saab kuulda valju hurjutamist. Hobuse nimi on Esku. Tema vaatab vaikides päält. (Millegipärast ei söandanud ma pilti teha sest lüpsmisest. Võib-olla kartsin, et selline pilt võiks Setomaale halba varju heita. Või põlistada nõnda selle jota-näoga nooreohtu naise, kes ometi meie vastu nii lahke oli.)

Sööming on jäänud hilja peale, kell on umbes kümme või rohkemgi. Linaga lauake kaetakse meile sinnasamasse, kus ennist istusime - sirelipõõsa alla.Kumbki saab kuhjaga taldrikutäie sousti-kartulit kurgi ja tomatisalatiga. Lisaks tuuakse toobitäis äsjalüpstud piima, mis mul kuidagi kurgust alla ei taha minna. Laua kõrval istub õnneks koer, kel on selline nägu peas, et ma lihtsalt pean oma piima talle andma. Salaja, muidugi. Ergo annab Mallele ühe eesti leiva, mille üle saajal silmnähtavalt hää meel on.

Laut on päris tee ääres - varisemisohtlik kiviehitis. Heinad on lauda peal. Vinname oma seljakotid redelist üles. On piisavalt pime, et mitte midagi näha. Lämbes virtsahaisus käsikaudu kobades teeme kuhugi mingi aseme. Juba on kuulda rottide jooksmist. Püüame uskuda Janekit, kes väidab, et nad heinte peale ei tule. Võtan igaks juhuks pihku noa, Ergo aga püksirihma, millega vajaduse korral äsada. Magamisest ei tule midagi välja. Tunneme, kuidas kirbud söövad. Aeg-ajalt kostub heinte seest (või pealt või alt...) krabinat. Jalad vajuvad kuhugi ära. Regulaarselt lõhub öövaikust koera kile klähvimine. Jutustame teineteisele ajaviiteks hulga "muinasjutte" ning alles koidu ajal õnnestub veidikeseks sõba silmale saada.

Läheb edasi...

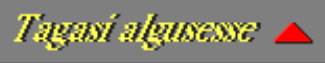

Ergo - Ergo Västrik, folklorist

Heiki - Heiki Valk, arheoloog, projekti "Seto usundilise pärimuse kogumine ja talletamine" (19941996) initsiaator ja koordinaator.

Ulrike - Ulrike Plath - Hamburgi Ülikooli ajaloo ja fennougristika üliõpilane.

Sammaspool - raskesti ravitav nahahaigus, ekseem. Ühe tekkepõhjusena on pakutud seda, et lehm on inimese peale inisenud. 